\title{
Hospital doctors' workflow interruptions and activities: an observation study
}

Matthias Weigl, Andreas Müller, Andrea Zupanc, Jürgen Glaser, Peter Angerer

Institute and Outpatient Clinic for Occupational, Social, and Environmental Medicine, LudwigMaximilians-University Munich, Munich, Germany

Correspondence to Matthias Weigl, Institute and Outpatient Clinic for Occupational, Social, and Environmental Medicine, Ludwig-MaximiliansUniversity Munich, Ziemssenstr. 1, D-80336 Munich, Germany; matthias.weigl@med.Imu.de

Accepted 10 August 2010 Published Online First 6 January 2011

\begin{abstract}
Background: Interruptions of hospital doctors' workflow are a frequent stressor, eventually jeopardising quality of clinical performance. To enhance the safety of hospital doctors' work, it is necessary to analyse frequency and circumstances of workflow interruptions. Aim: To quantify workflow interruptions among hospital doctors, identify frequent sources and relate sources to doctors' concurrent activities.

Methods: Within a typical hospital, 32 participant observations of doctors' full work shifts were carried out. Time-motion information was collected on types of workflow interruption and doctors' activities and analysed with logit-linear analyses.

Results: The frequency of workflow interruptions was high, especially on the intensive care unit and emergency ward. Telephones and bleepers were the most frequently recorded type of work interruption. The combined analysis of doctors' activities and concurrent workflow interruptions revealed that the likelihood of the occurrence of certain types of interruption depended on the tasks being carried out by the doctor.

Conclusion: The present method may be useful for quantifying and distinguishing sources of hospital doctors' workflow interruptions and useful in raising awareness of organisational circumstances.
\end{abstract}

\section{INTRODUCTION}

Workflow interruptions are a frequent stressor for doctors in hospitals. ${ }^{1-4}$ The consequences are manifold: they hamper the performance of duties and cause a constant challenge to task prioritisation, thus jeopardising the quality of clinical performance and eventually patient care. ${ }^{5}{ }^{6}$ Studies indicate that workflow interruptions can lead to dispensing errors in pharmacy, surgical errors, erroneous clinical decision making, disruptions of communication or poor hygienic behaviour. ${ }^{4} 8$ This may have an impact on patients' safety and the efficiency of work practices. ${ }^{2}$ Interruptions may hinder effective communication during various activities, such as registration procedures and shift changes. ${ }^{6}{ }^{9}$ It has been shown that work places with high levels of interruptions are perceived by employees as uncontrollable and unpredictable. ${ }^{10}{ }^{11}$ Interruptions are a source of fatigue, stress and frustration. ${ }^{12}$ A study among English general practitioners found that interruptions were one of the major stressors leading to lower job satisfaction. ${ }^{13}$

Most previous research on workflow interruptions has been carried out in emergency units ${ }^{3}{ }^{14-16}$ and operating theatres. ${ }^{4}$ 17-19 Doctors in emergency departments have been observed to be interrupted on average up to 10 times during a working hour. ${ }^{15}$ Interruptions on wards or intensive care units are frequent as well, though the pattern seems to differ [from emergency departments]; however, there is very little data to substantiate this. ${ }^{20-22}$

There is a need for more research analysing the frequency, character, and circumstances of interruptions. ${ }^{314}$ In other words, if we wish to reduce workflow interruptions and to establish work processes less liable to the negative consequences of interruptions, we need to know what kind of interruptions occur under which circumstances to understand the types of workflow interruptions, the likelihood of interruptions during certain activities, as well as their differential occurrence in different medical specialities. ${ }^{2} 172324$

The benefit of structured observational research in healthcare settings and patient research has been repeatedly emphasised. ${ }^{25} 26$ Observational measures are a useful way to quantify workflow interruptions. ${ }^{18} 27$ Timemotion studies are an adequate standard of clinicians' time and activity assessments. ${ }^{26} 28$ But only a few studies report a careful and valid measurement with defined inter-rater 
reliability. ${ }^{17}$ To obtain a sufficient level of precision and to promote internal validity, extended observations of greater time periods are needed. ${ }^{14}{ }^{26}$ Thus, full shift observations are a reliable and useful mean to obtain valid data on doctors' daily work routines. ${ }^{29}$

Based on a sample of doctors in a municipal hospital in Germany this study has the following aims:

(1) to assess the frequency of workflow interruptions

(2) to identify and quantify sources of work interruptions

(3) to relate sources of interruptions to doctors' work activities.

\section{METHOD}

\section{Study setting}

Participant observations were conducted in a 300-bed municipal teaching public hospital. It can be regarded as a typical German hospital in reference to official statistics. $^{30}$

The study was approved by the Ethics Committee of the Faculty of Medicine, Munich University, and by the department heads of the hospital. Measures were taken to protect personal data confidentiality. Only workflow interruptions and activities were recorded, and no patient-related information was collected or documented.

\section{Study sample and selection of observation dates}

The study focused on hospital doctors in surgery and internal medicine. Physicians currently undergoing or having completed specialist training were included. Eligible doctors (1) had to have worked at least 4 months at the hospital, and (2) had to be working entire shifts on a general ward, emergency ward or intensive careunit. (3) Senior and head doctors were excluded from the study. There were 32 eligible doctors within the four study departments. Participation was voluntary and verbal or written consent was obtained at least 1 day before the observation. Two doctors refused to participate. Only day shifts were chosen because clinicians are assigned to a specific department and clinical unit. On the interdisciplinary intensive care unit (ICU), day shifts are $12 \mathrm{~h}$; on wards and in the emergency ward (EW) $8.5 \mathrm{~h}$. In this particular hospital, internists were part of the staff of the ICU as well as the emergency ward.

The observation dates were selected randomly. Thirtytwo shifts were included in the study. Work shifts of 22 physicians were observed (Internal medicine, INT, $\mathrm{N}=13$; Surgery, SURG, $\mathrm{N}=9$ ). Of this group 10 doctors were observed twice. The majority were female doctors (INT: $61.5 \%$; SURG: $55.5 \%$ ). The mean tenure within the present hospital was about 7 years (INT: 7.0 years; standard deviation $(\mathrm{SD})=4.6$; SURG: 7.2 years; $\mathrm{SD}=6.0$ ). The percentage of doctors who have completed a specialist training was $37 \%$ (SURG) and $38.5 \%$ (INT).

\section{Measures: observation of workflow interruptions and doctors' activities}

During the participant observations specific information was collected on (1) source of workflow interruption and (2) type of activity.

\section{Assessment of workflow interruptions}

We define workflow interruptions as an intrusion of an unplanned and unscheduled task, causing a discontinuation of tasks, a noticeable break or task switch behaviour (ie, answering a phone call during patient's examination, responding to a nurse's question while charting). The initial task is suspended to perform an unplanned task, resulting in discontinuous task performance. ${ }^{31} 32$ Thus, an interruption means that an obvious barrier or obstacle in goal-directed behaviour occurs, hindering work performance, and attention resources have to be allocated to a break-in event. ${ }^{11} 33$ Impediments are another kind of workflow interruptions. Compared to interruptions that force physicians to stop the ongoing activity to turn their attention to a disruptive incident, impediments only aggravate or delay current task performance. ${ }^{33} 34$ In hospital work impediments are a frequent stressor and require additional effort. ${ }^{35}$ In this study we distinguish between information impediments (eg, patient's chart not at hand, diagnostic test results unavailable), waiting time (eg, in front of an elevator, a slow booting computer) and motor impediments (eg, ergonomic problems causing awkward movements).

Three steps were carried out to develop an observation instrument for workflow interruptions. First, we reviewed the available scientific literature and collected a list of potential sources. ${ }^{14-16} 2136$ Second, this collection was discussed with clinicians from various specialities to focus on most prevalent sources. Final categorisation was based upon a well-validated self-report instrument focussing on work conditions in hospitals. ${ }^{35}$ Third, nonsystematic participant observations were carried out to test the instrument's applicability as well as to discuss scoring problems. As a result, 10 sources of interruptions were specified (see table 1 ).

\section{Type of doctors' activities}

Doctors' activities were recorded with a standard observation instrument ${ }^{37}$ and broken down into seven main task categories: (1) direct patient communication, (2) diagnostic activities, (3) therapy, (4) documentation, (5) conversation with staff, (6) conversation with others and (7) other activities (eg, taking breaks). 
Table 1 Sources and definition of workflow interruptions in hospital doctors

\begin{tabular}{|c|c|c|c|}
\hline Category & & Workflow interruption & Definition: significant disturbance due to ... \\
\hline \multirow[t]{2}{*}{$\begin{array}{l}\text { Colleague } \\
\text { interruptions }\end{array}$} & 1 & Interruptions by doctors & $\begin{array}{l}\text {... other doctors' actions (eg, colleague asking for } \\
\text { patients charts). }\end{array}$ \\
\hline & 2 & Interruptions by nursing staff & ... nursing staff's actions (including nursing trainees) \\
\hline $\begin{array}{l}\text { Telephone/ } \\
\text { bleeper }\end{array}$ & 3 & Interruptions by telephone/bleeper & ... telephone or bleeper call and subsequent responding \\
\hline Interruption & 4 & Interruptions by patients & ... patients (eg, patient asks for information) \\
\hline \multirow[t]{3}{*}{ by others } & 5 & $\begin{array}{l}\text { Interruptions by patients' } \\
\text { relatives }\end{array}$ & $\begin{array}{l}\text {... patients' relatives (eg, relatives stopping doctors in } \\
\text { hospital corridors) }\end{array}$ \\
\hline & 6 & Interruptions by others & $\ldots$ any other person (ie, physical therapist, social worker) \\
\hline & 7 & $\begin{array}{l}\text { Interruptions due to equipment } \\
\text { or technical malfunctions }\end{array}$ & $\begin{array}{l}\text {... equipment dysfunctions or technical malfunctions } \\
\text { (ie, computer system crash; failure of blood gas analysis) }\end{array}$ \\
\hline \multirow[t]{3}{*}{$\begin{array}{l}\text { Impediments/ } \\
\text { delays }\end{array}$} & 8 & Information impediments & $\begin{array}{l}\text {... necessary work information unavailable (ie, patient's chart } \\
\text { or diagnostic findings not available, forms not in stock etc) }\end{array}$ \\
\hline & 9 & Waiting time & $\begin{array}{l}\text {... waiting time to continue current workflow (ie, waiting } \\
\text { for elevator) }\end{array}$ \\
\hline & 10 & Motor impediments & $\begin{array}{l}\text {... physical impediments (ie, noise, additional physical } \\
\text { strengths in moving heavy patients) }\end{array}$ \\
\hline
\end{tabular}

\section{Test of instrument's reliability}

Within a pilot study the instrument's reliability was tested. Six hospital doctors working on wards and in the EW (three internists, three surgeons) were observed by two trained raters simultaneously (six observation periods; range 34.5-69 min; sum $291.5 \mathrm{~min}$ ). A total of 101 workflow interruptions were coded (Rater 1 : $\mathrm{N}=47$; Rater 2: $\mathrm{N}=54)$. The resulting $\kappa$-coefficient was 0.65 $(\mathrm{T}=23.9 ; \mathrm{p}=0.00)$. This is considered substantial agreement and underlines the instrument's good reliability. ${ }^{38}$

\section{Procedure, data collection and analysis}

Two trained observers shadowed the doctors during the shift, recorded activities, the actual time spent on activities, as well as workflow interruptions. To minimise observational effects, the observers kept an appropriate distance $^{39}$ and were instructed not to interrupt doctors or co-working staff (eg, not to start a conversation).

Data were recorded on clipboard paper sheets, transferred via double data entry into a database, and checked for correctness and implausible values. Subsequent data analyses were performed using SPSS 17.0. Because of the exploratory nature of our study, no multiplicity adjustment was applied. For inferential statistics to explore group differences, Mann-Whitney U Test was used. To explore the likelihood of interruptions under the condition of different activity categories, we used logit-linear model analysis. ${ }^{40}$ This procedure compares the unconditional probability that a workflow interruption happens at any activity with the conditional probability of this interruption occurring during one of the seven activities. Statistical significance is based on $\chi^{2}$ tests, checking the relationship between the two variables. ${ }^{41}$

\section{RESULTS}

Hospital doctors were observed during 32 full work shifts, with an overall duration of $277.4 \mathrm{~h}$ (16662.2 min). The average shift duration was about $8 \mathrm{~h} 40 \mathrm{~min}$ (SD, $1 \mathrm{~h}$ $47 \mathrm{~min}$; range $4 \mathrm{~h} 54 \mathrm{~min}-14 \mathrm{~h} 05 \mathrm{~min}$ ).

\section{Frequency of observed workflow interruptions}

About 1480 workflow interruptions were observed. The following table 2 presents the frequency of workflow interruptions, grouped by clinical speciality and area in the hospital.

On average, we observed about 5.3 workflow interruptions per work hour, which means that hospital doctors' workflow was disrupted every $11.25 \mathrm{~min}$. A significant difference regarding clinical speciality was observed: The workflow of the internists was significantly more interrupted than their colleagues in the surgery departments $(\mathrm{Z}=-2.66 ; \mathrm{p}=0.01)$. According to the $\mathrm{SD}$ we found a greater variation of average hourly interruptions within surgery than internal medicine. Regarding areas in the hospital, disruptions occur at ICU and EW more frequently than on the ward. Because the sample size was too small (only three full shift observations at ICU), significance testing wasn't carried out completely. Only differences between ward and EW were tested.

\section{Sources of doctors' workflow interruptions}

Out of the 1480 workflow interruptions observed, most were caused by nurses $(\mathrm{N}=551 ; 37.2 \%)$, followed by telephone/bleeper calls $(\mathrm{N}=324 ; 21.9 \%)$, then fellow doctors $(\mathrm{N}=257 ; 17.4 \%)$. Other person-related interruptions $(\mathrm{N}=194 ; 13.1)$ were attributed to patients $(\mathrm{N}=31 ; 2.1 \%)$, patients' relatives $(\mathrm{N}=35 ; 2.4 \%)$ and 


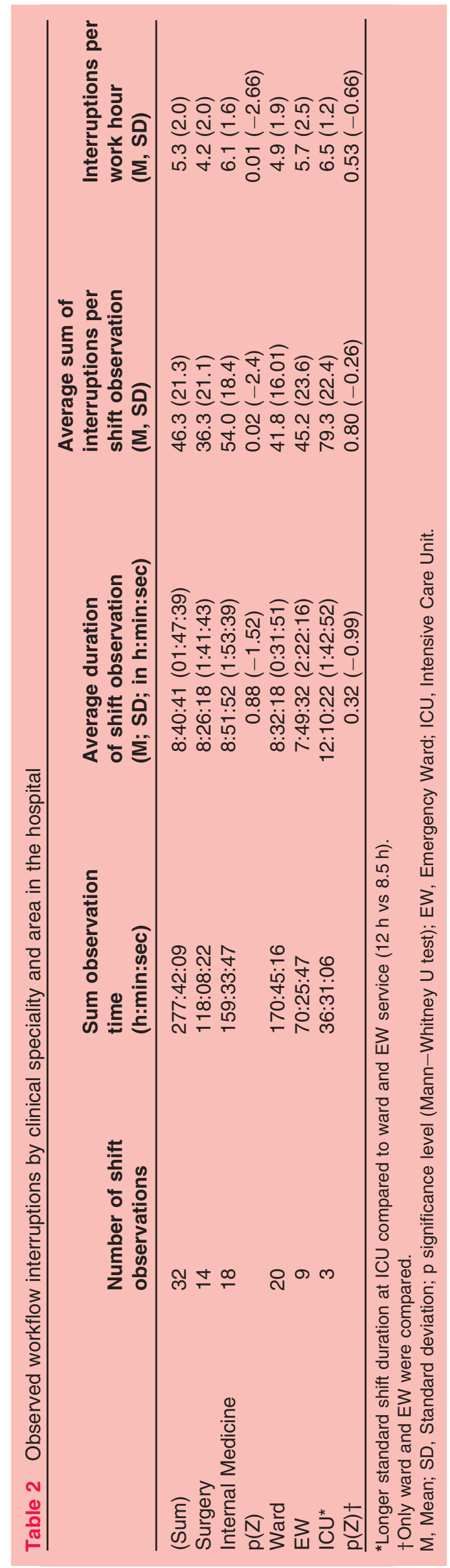

other persons $(\mathrm{N}=91 ; 6.1 \%)$. Interruptions due to impediments or delays $(\mathrm{N}=154 ; 10.4 \%)$ can be divided into either interruptions due to equipment or technical malfunctions $(\mathrm{N}=37 ; 2.5 \%)$, to information impediments $(\mathrm{N}=118 ; 8.0 \%)$, to waiting time $(\mathrm{N}=15 ; 1.0 \%)$, or to motor impediments $(\mathrm{N}=21 ; 1.4 \%)$. Afterwards the sources of workflow interruptions were categorised (cf. table 3).

\section{Hospital doctors' activities and concurrent workflow interruptions}

To address the likelihood of being interrupted during certain activities, a cross-table of the type of physician activities and concurrent task disruptions, categorised by source, was computed. All interrupting events $(\mathrm{N}=1480)$ as well as the concurrent physician activities $(\mathrm{N}=4163)$ were taken into account.

Table 3 presents frequencies of concurrent workflow interruptions and doctors' activities. Four combinations cover almost half of all observed events: interruptions by nurses $(\mathrm{N}=302 ; 20.4 \%)$, interruptions by fellow doctors $(\mathrm{N}=179 ; 12.1 \%)$, by bleepers/telephone $(\mathrm{N}=131 ; 8.9 \%)$ and other sources $(\mathrm{N}=106 ; 7.2 \%)$, all happening during documentation and charting activities.

In a second step we examined which type of interruption is more likely to occur when a certain activity is going on (ie, a certain task performance by a physician; cf. table 3). The cell probabilities represent the likelihood of a certain workflow interruption in each of the seven categories of doctors' activities. The accumulated probabilities at the bottom row are the overall probability that a workflow interruption occurs due to a certain cause; the accumulated probabilities in the right column represent the probability of this occurring during a certain activity of the physicians. Bold probabilities indicate that an observed workflow interruption is significantly more likely to occur if the respective activity is being performed (ie, conditional probability of a workflow interruption; cf. table 3). Workflow interruptions due to telephone or bleeper calls occurred significantly more often, when doctors were communicating with patients or were engaged in other activities. Impediments were also significantly more likely to occur when conversations with ward staff or others were observed. Significantly lower probabilities of workflow interruptions occurred in case, presented as shaded in table 3: Interruptions by doctors' colleagues were less likely when physicians were engaged in conversations with patients, or staff, and during other activities. Interruptions by nurses tended to be less likely when physicians were performing other activities (like meetings, teaching). Telephone or bleeper interruptions and impediments were less probable, when doctors were engaged in documentation activities. 
Table 3 Number and conditional probabilities of observed physician activities and workflow interruptions (logit-linear analysis, $\mathrm{N}=1480$ )

\begin{tabular}{|c|c|c|c|c|c|c|}
\hline \multirow[b]{2}{*}{ Physician activities } & \multicolumn{5}{|c|}{ Sources of workflow interruptions } & \\
\hline & $\begin{array}{c}\text { Interruptions } \\
\text { by doctors }\end{array}$ & $\begin{array}{c}\text { Interruptions } \\
\text { by nurses }\end{array}$ & $\begin{array}{l}\text { Interruptions } \\
\text { by telephone }\end{array}$ & $\begin{array}{c}\text { Interruptions } \\
\text { by others }\end{array}$ & Impediments & \\
\hline & $\mathrm{N}$ ( $\left.\mathrm{p}_{\text {cond }}\right)$ & $\mathrm{N}$ ( p $\left._{\text {cond }}\right)$ & $N\left(p_{\text {cond }}\right)$ & $\mathrm{N}$ ( p $\left._{\text {cond }}\right)$ & $N\left(p_{\text {cond }}\right)$ & Total N (punc) \\
\hline $\begin{array}{l}\text { Communication to } \\
\text { patient }\end{array}$ & $6\left(0.06^{\star \star}\right)$ & $37(0.38)$ & $29\left(0.30^{*}\right)$ & $10(0.10)$ & $15(0.15)$ & $97(0.07)$ \\
\hline Diagnostics & $15(0.13)$ & $51(0.43)$ & $21(0.18)$ & $20(0.17)$ & $11(0.09)$ & $118(0.08)$ \\
\hline Therapy & $9(0.15)$ & $29(0.48)$ & $12(0.20)$ & $1\left(0.02^{* *}\right)$ & $10(0.16)$ & $61(0.04)$ \\
\hline Documentation & $179(0.23)$ & $302(0.39)$ & $131\left(0.17^{\star \star}\right)$ & $106(0.14)$ & $57\left(0.07^{\star \star}\right)$ & $775(0.52)$ \\
\hline Conversation with staff & $34\left(0.13^{*}\right)$ & $92(0.34)$ & $66(0.24)$ & $34(0.13)$ & $44\left(0.16^{* \star}\right)$ & $270(0.18)$ \\
\hline $\begin{array}{l}\text { Conversation with } \\
\text { others }\end{array}$ & $1(0.04)$ & $6(0.22)$ & $10(0.37)$ & $2(0.07)$ & $8\left(0.30^{* *}\right)$ & $27(0.02)$ \\
\hline Other activities & $13\left(0.10^{*}\right)$ & $34\left(0.26^{\star \star}\right)$ & $55\left(0.42^{\star *}\right)$ & $21(0.16)$ & $9(0.07)$ & $132(0.09)$ \\
\hline Total N (punc) & $257(0.17)$ & $551(0.37)$ & $324(0.22)$ & $194(0.13)$ & $154(0.10)$ & $1480(1)$ \\
\hline
\end{tabular}

Bold: probability of a workflow interruption under the condition of a specific physician activity (conditional probability) is significantly higher than the unconditional probability of the workflow interruption.

Shaded: probability significantly lowered than expected.

Significance levels of adjusted residuals: ${ }^{*} p<0.05 ;{ }^{* *} p<0.01$.

$\mathrm{N}=1480 ; p_{\text {cond }}$, conditional probability; $\mathrm{p}_{\text {unc }}$, unconditional probabilities.

\section{DISCUSSION}

A new instrument for observation and assessment of hospital doctors' work was developed. Participant observations enable reliable quantification of different sources of workflow interruptions in hospital physicians' routine care. Based on 32 full shift observations of doctors' work on internal and surgery wards of a typical hospital in Germany, it is shown that doctors are interrupted on average 5.3 times per hour of work (every $11.25 \mathrm{~min}$ ) and that most interruptions occur during documentation and charting. The most frequent source is the nursing staff. There is considerable variance in the frequency and the source of interruption depending on what kind of activity doctors were involved in.

This study makes three important contributions: First, it quantifies via reliable measures workflow interruptions in a regular care setting. It was observed, that every 11 min a workflow disruption occurs. This means doctors act within a work environment with a high potential for distracting events. Regarding clinical speciality, internists faced significantly more interruptions than their colleagues in surgery disciplines, outside of the operation theatre. Regarding the specific area in the hospital, doctors working in ICUs and on EWs were also observed to deal with (statistically non-significant) more frequent workflow interruptions. This result is in line with previous observations. ${ }^{14} 31$

Second, the results reveal the relative contribution of different sources of workflow interruptions. ${ }^{18}{ }^{36}$ Half of all observed workflow interruptions were attributable to nurses and telephone/bleeper calls. On the one hand, this reflects a high requirement for communication within interdisciplinary care environments. ${ }^{20}$ On the other hand, it reveals opportunities to reduce unnecessary interruptions ${ }^{31}$ and to reflect on staff's adoption of 'interruptive communication mechanisms'. ${ }^{22}$

Third, this study combines for the first time physician activities with concurrent frequencies and sources of workflow interruptions. The aim was to identify activities with an increased risk of workflow interruptions that can be considered as 'inefficient work practices'. ${ }^{3}$ The results show that indeed the performance of specific physician activities increases the likelihood of selected workflow interruptions. These incidents may also be associated with a high potential of impaired performance, detrimental results or compromised patient safety. ${ }^{2}$ Most interruptions were observed during documentation and charting activities. This is a time-consuming part of doctors' work in Germany. ${ }^{42}$ Work design approaches are needed that help provide opportunities to document and chart without frequent disruptions.

The results of our study should be interpreted in the light of several limitations. The present study is based on a single sample. Although in Germany the work practices of clinical specialities are mainly comparable between hospitals, there may have been a selection bias. Both the activities of physicians and the frequency of interruptions are likely to vary depending on hospital type, a department's quality of work organisation and the doctors' duties. Furthermore, there is a disproportion in our sampling of wards, emergency and IC units, which limits the comparison of the units as well as it affects the sub-analysis (cf. table 3), since the source of interruption may be nested within the type 
of area. And although we undertook various measures to reduce observer effects (ie, Hawthorne effect; cf. Methods), a potential observer bias may influence doctors' and co-workers activity patterns (eg, tendency to take breaks, colleagues' tendency to interrupt).

Careful interpretation of the category "interruptions" is also necessary. In our case, only clearly observed workflow interruptions were registered. One interruption event may not be the equivalent of another. Some workflow interruptions have more significant safety implications than others. ${ }^{43}$ Workflow interruptions caused by co-workers (ie, nurses, doctors or others) may also have positive effects on a ward's workflow, enabling better clarification, error capture (eg, 'to speak up' if something is wrong) or an immediate response to incoming emergencies. In such cases, there may be a 'reflexive' or 'self-regulating' quality to co-workers interruptions, as colleagues are able to pick a time when it is appropriate to interrupt. In contrast, 'random' interruptions (such as phone calls or technical malfunctions) occur more accidently or arbitrarily. Thus, it can be assumed that 'random' interruptions are more strongly related to work impairments than 'reflexive' interruptions. Moreover, the doctors' perception of observed interruptions may differ substantially depending on the frequency and the severity, ${ }^{1}$ temporal extent, ${ }^{18}$ and source of interruptions. ${ }^{17}$ Thus no conclusions regarding potential individual and performance outcomes of workflow interruption can be drawn from the present study. This equally applies to potential positive appraisals of workflow interruptions, as when an interruption alerts physicians about a patient's critical condition or provides necessary information for subsequent tasks. ${ }^{14}$

Cautious interpretation is also necessary regarding the coincidence of doctors' activities and workflow interruptions; the present study examines only the concurrence of both events but doesn't assume causality or mutual interdependence.

Nevertheless, differentiating between sources of workflow interruptions suggests several implications and opportunities for intervention. To reduce frequent workflow interruptions caused by nurses, a thorough analysis and deliberate re-design of doctor-nurse communication and coordination is essential. Regular coordination, adjusted care processes, communication policies and organised information transfer, for example, may reduce future mistimed enquiries. ${ }^{9} 22$ In order to reduce 'random' telephone or bleeper interruptions, electronic assistance and IT solutions may be a promising approach (eg, electronic whiteboards), as long they are applied well considered and in combination with human behaviour-based interventions. ${ }^{36}$

Physicians' work in healthcare systems is dynamic and performance impairments or errors are not captured by single causes but rather arise under complex conditions $^{44}$ : The assessment of work interruption in the context of physicians' activities gives due attention to this and offers opportunities to identify tasks which are prone to error or impaired performance. ${ }^{3}$ Future research should investigate the situations in which situations doctors' psychological capacity to cope with interruptions or distractions may be critically impaired. Memory processes, depending on vigilance among others, may play an important role in the resumption of interrupted tasks. ${ }^{2}$ Finally, addressing work interruptions may improve doctors work life in the hospital and effectively reduce psychophysical strain. ${ }^{11}$ Besides the above-mentioned detrimental outcomes and compromised patient safety, there might also be positive consequences of workflow interruptions (cf. discussion of study's limitations). More applied studies are necessary to address potential positive effects like reduced feelings of monotony, ${ }^{5}$ enhanced time for problem solving ${ }^{45}$ or perceived effectiveness of intrusion events. ${ }^{46}$ Also outcome measures assessing patient's satisfaction may be of further interest. ${ }^{47}$ Communication requirements and individual perspectives of the concerned persons must be taken into account when reorganisation of work processes is planned.

\section{CONCLUSIONS}

Participant observation of doctors' work during full shifts allows us not only to determine the frequency of interruption, but also to identify the source of interruption and the work context in which the interruption occurs. Such participant observation may serve as a solid basis for the improvement of work organisation, leading to improved hospital performance, and help identify environmental, work-related factors in the hospital that contribute to the overall quality and safety of healthcare performance. $^{18} 48$

Funding The study was funded by the German Medical Association (Grant No. 06-73) and the Munich Center of Health Sciences.

Competing interests None.

Patient consent Obtained.

Ethics approval This study was conducted with the approval of the Munich University, Ethics Committee of the Medical Faculty.

Provenance and peer review Not commissioned; externally peer reviewed.

\section{REFERENCES}

1. Sevdalis N, Forrest D, Undre S, et al. Annoyances, disruptions, and interruptions in surgery: the Disruptions in Surgery Index (DiSI). World J Surg 2008;32:1643-50.

2. Grundgeiger T, Sanderson P. Interruptions in healthcare: theoretical views. Int J Med Inf 2009;78:293-307.

3. Laxmisan A, Hakimzada F, Sayan OR, et al. The multitasking clinician: decision-making and cognitive demand during and after team handoffs in emergency care. Int J Med Inform 2007;76:801-11.

4. Wiegmann DA, EIBardissi AW, Dearani JA, et al. Disruptions in surgical flow and their relationship to surgical errors: an exploratory investigation. Surgery 2007;142:658-65. 
5. Jett QR, George JM. Work interrupted: a closer look at the role of interruptions in organizational life. Acad Manage Rev 2003;28:494-507.

6. Hakimzada AF, Green RA, Sayan OR, et al. The nature and occurrence of registration errors in the emergency department. Int $J$ Med Inform 2008;77:169-75.

7. Flynn EA, Barker KN, Gibson JT, et al. Impact of interruptions and distractions on dispensing errors in an ambulatory care pharmacy. Am J Health Syst Pharm 1999;56:1319-25.

8. Biros MH, Adams JG, Wears RL. Errors in emergency medicine: a call to action. Acad Emerg Med 2000;7:1173-4.

9. Patterson ES, Roth EM, Woods DD, et al. Handoff strategies in settings with high consequences for failure: lessons for health care operations. Int J Qual Health Care 2004;16:125-32.

10. Kirmeyer SL. Coping with competing demands: interruption and the type A pattern. J Appl Psychol 1988;73:621-9.

11. Zijstra FRH, Roe RA, Leonora AB, et al. Temporal factors in mental work: Effects of interrupted activities. Journal of Occupational and Organizational Psychology 1999;72:163-85.

12. Tucker AL, Spear SJ. Operational failures and interruptions in hospital nursing. Health Serv Res 2006;41:643-62.

13. Cooper CL, Rout U, Faragher B. Mental health, job satisfaction, and job stress among general practitioners. BMJ 1989;298:366-70.

14. Chisholm CD, Collison EK, Nelson DR, et al. Emergency department workplace interruptions: are emergency physicians "interrupt-driven" and "multitasking"? Acad Emerg Med 2000;7:1239-43.

15. Chisholm CD, Dornfeld AM, Nelson DR, et al. Work interrupted: a comparison of workplace interruptions in emergency departments and primary care offices. Ann Emerg Med 2001;38:146-51.

16. Levin S, France DJ, Hemphill R, et al. Tracking workload in the emergency department. Hum Factors 2006:48:526-39.

17. Healey AN, Sevdalis N, Vincent CA. Measuring intra-operative interference from distraction and interruption observed in the operating theatre. Ergonomics 2006:49:589-604.

18. Healey AN, Primus CP, Koutantji M. Quantifying distraction and interruption in urological surgery. Qual Saf Health Care 2007; $16: 135-9$.

19. Zheng B, Martinec DV, Cassera MA, et al. A quantitative study of disruption in the operating room during laparoscopic antireflux surgery. Surg Endosc 2008;22:2171-7.

20. Westbrook JI, Ampt A, Kearney L, et al. All in a day's work: an observational study to quantify how and with whom doctors on hospital wards spend their time. Med J Aust 2008;188:506-9.

21. Tang Z, Weavind L, Mazabob J, et al. Workflow in intensive care unit remote monitoring: a time-and-motion study. Crit Care Med 2007;35:2057-63.

22. Coiera $\mathrm{E}$, Tombs V. Communication behaviours in a hospital setting: an observational study. BMJ 1998;316:673-6.

23. Brixey JJ, Robinson DJ, Johnson CW, et al. Towards a hybrid method to categorize interruptions and activities in healthcare. Int $J$ Med Inform 2007;76:812-20.

24. Alvarez G, Coiera E. Interruptive communication patterns in the intensive care unit ward round. Int J Med Inform 2005;74:791-6.

25. Carthey J. The role of structured observational research in health care. Qual Saf Health Care 2003;12(Suppl 2):ii13-16.

26. Finkler SA, Knickman JR, Hendrickson G, et al. A comparison of work-sampling and time-and-motion techniques for studies in health services research. Health Serv Res 1993;28:577-97.
27. Thomas EJ, Sexton JB, Helmreich RL. Translating teamwork behaviours from aviation to healthcare: development of behavioural markers for neonatal resuscitation. Qual Saf Health Care 2004:13(Suppl 1):i57-64.

28. Bratt JH, Foreit J, Chen PL, et al. A comparison of four approaches for measuring clinician time use. Health Policy Plan 1999;14:374-81.

29. Gilchrist V, McCord G, Schrop SL, et al. Physician activities during time out of the examination room. Ann Fam Med 2005;3:494-9.

30. Krankenhäuser [Hospitals] [database on the Internet]. Statistisches Bundesamt Deutschland [Federal Statistical Office Germany], 2006. http://www.destatis.de (accessed 14 Jul 2008).

31. Brixey JJ, Tang Z, Robinson DJ, et al. Interruptions in a level one trauma center: a case study. Int J Med Inform 2008;77:235-41.

32. Brixey JJ, Robinson DJ, Johnson CW, et al. A concept analysis of the phenomenon interruption. ANS Adv Nurs Sci 2007;30:E26-42.

33. Greiner BA, Ragland DR, Krause N, et al. Objective measurement of occupational stress factors-an example with San Francisco urban transit operators. J Occup Health Psychol 1997;2:325-42.

34. Frese M, Zapf D. Action as the core of work psychology: A German approach. In: Dunnette MD, Hough LM, Triandis HC, eds. Handbook of industrial and organizational psychology. 2nd edn. Palo Alto, CA: Consulting Psychologists Press, 1994:271-340.

35. Büssing A, Glaser J. Das Tätigkeits-und Arbeitsanalyseverfahren für das Krankenhaus-Selbstbeobachtungsversion (TAA-KH-S) [Activity and work analysis in hospitals-self report version (TAA-KH-S)]. Göttingen: Hogrefe, 2002.

36. France DJ, Levin S, Hemphill R, et al. Emergency physicians' behaviors and workload in the presence of an electronic whiteboard. Int J Med Inform 2005;74:827-37.

37. Weigl M, Muller A, Zupanc A, et al. Participant observation of time allocation, direct patient contact, and simultaneous activities in hospital physicians. BMC Health Serv Res 2009;9:110.

38. Landis JR, Koch GG. Measurement of observer agreement for categorical data. Biometrics 1977;33:159-74.

39. Hollingsworth JC, Chisholm CD, Giles BK, et al. How do physicians and nurses spend their time in the emergency department? Ann Emerg Med 1998;31:87-91.

40. Bakeman R, Adamson LB, Strisik P. Lags and logs: approaches to interaction (SPSS Version). In: Gottman JM, ed. The analysis of change. Mahwah, NJ: Lawrence Erlbaum, 1995:279-308.

41. Gottman JM, Roy AK. Sequential Analysis. A Guide for Behavioral Researchers. Cambridge: Cambridge University Press, 1990.

42. Blum K, Muller U. [Time spent on documentation during physicians' service in hospitals. Representative increase of the German Hospital Institute]. Chirurg 2003;74:276-80.

43. Kreckler S, Catchpole K, Bottomley M, et al. Interruptions during drug rounds: an observational study. Br J Nurs 2008;17:1326-30.

44. Hollnagel E. Barriers and Accident Prevention. Aldershot, England: Ashgate Publisher, 2004.

45. Sio UN, Ormerod TC. Does incubation enhance problem solving? A meta-analytic review. Psychol Bull 2009;135:94-120.

46. Rogelberg SG, Leach DJ, Warr PB, et al. "Not another meeting!" Are meeting time demands related to employee well-being? J Appl Psychol 2006;91:83-96.

47. Dearden $A$, Smithers $M$, Thapar $A$. Interruptions during general practice consultations-the patients' view. Fam Pract 1996;13:166-9.

48. Wilson JR. Fundamentals of ergonomics in theory and practice. Appl Ergon 2000;31:557-67. 
BMJ Quality

\& Safety

\section{Hospital doctors' workflow interruptions and activities: an observation study}

Matthias Weigl, Andreas Müller, Andrea Zupanc, Jürgen Glaser and Peter Angerer

BMJ Qual Saf 2011 20: 491-497 originally published online January 6, 2011

doi: $10.1136 /$ bmjqs.2010.043281

Updated information and services can be found at:

http://qualitysafety.bmj.com/content/20/6/491

\section{Notes}

\section{These include:}

References This article cites 42 articles, 12 of which you can access for free at: http://qualitysafety.bmj.com/content/20/6/491\#BIBL

Email alerting Receive free email alerts when new articles cite this article. Sign up in the service box at the top right corner of the online article.

To request permissions go to:

http://group.bmj.com/group/rights-licensing/permissions

To order reprints go to:

http://journals.bmj.com/cgi/reprintform

To subscribe to BMJ go to:

http://group.bmj.com/subscribe/ 